\title{
Jan PEKELDER
}

ORCID: 0000-0002-7256-736X

Univerzita Karlova v Praze \& Université Paris-Sorbonne

\section{Iconische, taalkundige en pragmatische volgordes in het Nederlands. Met speciale aandacht voor het Frans}

\begin{abstract}
This contribution is methodological in nature. We aim to address the question of the nature of the parameters underlying word order in Dutch with particular reference to French. We assume that there are basically three parameters to consider: an iconic parameter, a linguistic parameter and a pragmatic parameter. The iconic parameter concerns the projection of general human habits on the word order. The linguistic parameter is related to the word orders which mark language-specific but situation-free syntactic or semantic relations between word groups. Finally, the pragmatic parameter addresses the link between the communicative situation and the language-dependent word order phenomena.
\end{abstract}

Keywords: word order, iconic, linguistic and pragmatic parameters, Dutch, French.

\section{Inleiding}

De observatie dat zinsuitingen per definitie onderdeel zijn van een communicatieve situatie betekent uiteraard niet dat woordvolgorde volledig bepaald wordt door pragmatische factoren. Zoals bekend doen ook taalkundige - i.e. syntactische en semantische - factoren hun invloed gelden. Ten laatste mag men niet vergeten dat sommige volgordepatronen iconisch zijn: ze weerspiegelen algemeen cognitieve habits (Van der Horst 1995; Pekelder 2002). Een van de uitdagingen voor het syntactisch onderzoek is de identificatie van de genoemde factoren. Er bestaat bij ons weten echter geen algemeen geaccepteerd protocol dat de onderzoeker in staat zou stellen in talen de iconische, taalkundige en pragmatische factoren te onderscheiden. Doel van deze bijdrage is een methodologische reflectie te bieden met betrekking tot een dergelijk protocol. 


\section{Theoretisch kader}

We gaan uit van een functionalistisch kader (Martinet 1985; Builles 1998). Onze vraag luidt: hoe slaagt de ontvanger erin de door de zender gecodeerde boodschap zodanig te decoderen dat er sprake is van communicatie? Dankzij het onderzoek van diverse generaties syntactici weten we dat zinsuitingen verschillende aanwijzingen bevatten die de ontvanger in staat stellen deze zowel syntactisch, semantisch als pragmatisch te decoderen (Paul 1920; De Groot 1949; Nieuwborg 1968; Van der Lubbe 1978; Martinet 1985; Paardekooper 1986; Van der Horst 1995; Builles 1998; Ebeling 2006). Deze aanwijzingen zijn globaal genomen van tweeërlei aard: discreet en niet-discreet. Onder de eerste categorie laten we de isoleerbare vorm-betekenis-eenheden vallen. Dit zijn gebonden en vrije morfemen, woorden en woordgroepen, alsmede hun al dan niet vaste positie, onderlinge plaatsing, en fonologie. Onder niet-discrete aanwijzingen verstaan we betekenissen van gebonden en vrije morfemen, woorden en woordgroepen, inclusief hun interpretatie onder invloed van de communicatieve situatie. In overeenstemming met het voorafgaande concentreren we ons hier op de discrete aanwijzingen en daarbinnen de onderlinge plaatsing van woordgroepen in het Nederlands. ${ }^{1}$ Alvorens over te gaan tot een presentatie van voornoemde iconische, taalkundige en pragmatische factoren, herinneren $\backslash$ we eraan dat volgorde in eerste instantie een natuurlijk verschijnsel is. Door het vocale karakter van menselijke taal volgen de klanken elkaar noodzakelijkerwijs in de tijd op. Uhlenbeck (1982) hanteert in dit verband de term 'temporele volgorde'. ${ }^{2}$ Dit betekent dat volgorde a priori noch iconisch, noch taalkundig, noch pragmatisch is. ${ }^{3}$

\section{Iconische factoren: noch taal-, noch situatiegebonden}

Iconische factoren betreffen de verbinding tussen een woordgroep $\mathrm{x}$ en een cognitieve habit y. Toegepast op woordvolgorde betekent dit dat de positie van een

${ }^{1}$ Voor een gedetailleerde beschrijving verwijzen we naar Pekelder (2002).

${ }^{2}$ Martinet spreekt over het zogenaamde Principe de Linéarité (1985). Terzijde wijzen we erop dat de frequent gehanteerde termen 'links' en 'rechts' bijgevolg onjuist zijn (vergelijk Haeseryn e.a. 1997). Deze zijn immers gebaseerd op de spelling. Wij schrijven van links naar rechts. Uitgaande van de temporele volgorde dienen daarom de termen 'voor' en 'achter' te worden gebruikt: in de spraak volgt de ene klank op de andere.

${ }^{3}$ Het is nuttig in dit kader te wijzen op een oud maar nog steeds actueel statement van De Groot: "Misschien is het niet geheel overbodig er nog eens de nadruk op te leggen, dat woordvolgorde en syntactische structuur volkomen verschillende dingen zijn" (De Groot 1949: 67). Met andere woorden: aan woordvolgorde is niet uitsluitend syntactische structuur af te lezen. Het omgekeerde geldt ook: syntactische structuur wordt niet uitsluitend gemarkeerd door woordvolgorde. Zie Pekelder (2002). 
woordgroep $\mathrm{x}$ als een weerspiegeling wordt beschouwd van de verbinding met $\mathrm{y}$. We spreken dan van de iconische functie van $\mathrm{x}$. Iconische factoren zijn niet gebonden aan een specifieke taal of zelfs taalfamilie, noch aan een specifieke communicatieve situatie. Een bekend voorbeeld is het Complexiteitsprincipe (Dik 1997; Haeseryn e.a. 1997; Pekelder 2002). Dit principe gaat terug op Behaghel (1909) en betreft zowel de fonotaxis als de syntagmatiek. ${ }^{4} \mathrm{Zie}(1)$ voor een formulering. ${ }^{5}$

(1) moedertaalsprekers hebben de neiging complexe woordgroepen achter minder complexe te plaatsen. Deze tendens weerspiegelt de habit het complexe te benaderen uitgaande van het minder complexe, eerder dan omgekeerd (Pekelder 2002: 23).

Dat het hier inderdaad om een niet taalgebonden volgordeverschijnsel gaat, blijkt uit de observatie dat talen uit verschillende families gelijksoortige tendensen laten zien (Behaghel 1909; Dik 1997; Abeillé en Godard 2006). Zie de Engelse $(\mathrm{n}=267.000)$, Duitse $(\mathrm{n}=77.250)$, Franse $(\mathrm{n}=77.880)$ en Tsjechische $(\mathrm{n}=31.158)$ data in (2a)-(5b) waar de complexere tijdsbepalingen at 9 o'clock, um 9 Uhr, à 9 heures en $v 9$ in de meerderheid van de gevallen op de minder complexe tomorrow, morgen, demain en zitra volgen. ${ }^{6}$

(2a) [tomorrow] [at [9 o'clock]] (61\%)

(2b) [at [9 o'clock]] [tomorrow] (39\%)

(3a) [morgen] [um [9 Uhr]] (89\%)

(3b) [um [9 Uhr]] [morgen] (11\%)

(4a) [demain] [à [9 heures]] (95\%)

(4b) [à [9 heures]] [demain] (5\%)

(5a) [zítra] [v [9]] (99\%)

(5b) [v [9 ]] [zítra] (1\%)

${ }^{4}$ Zoals duidelijk moge zijn, laten we de fonotaxis hier buiten beschouwing.

${ }^{5}$ Met betrekking tot het concept 'complexiteit' hanteren we hier de volgende werkdefinitie: een woordgroep $\mathrm{x}$ is complexer dan een woordgroep y indien $\mathrm{x}$ meer inbeddingen bevat dan $\mathrm{y}$. Een woordgroep als [om [15.00 uur]] is dus complexer dan de woordgroep [morgen] omdat in de eerste $15.00 \mathrm{uur}$ is ingebed in om $15.00 \mathrm{uur}$, terwijl morgen geen interne syntactische structuur heeft. Voor een problematisering van het complexiteitsconcept, zie Wasow (1997).

${ }^{6}$ Voor alle data onder (2a)-(5b) geldt: $\mathrm{p}<0.001$. Consultatie Google: 11 mei 2017 (alleen adjacente woordgroepen). 
We nemen aan dat het Complexiteitsprincipe tevens niet situatiegebonden is. Zie (6a)-(8b) die aan onze informanten zijn aangeboden zonder geëxpliciteerde communicatieve situatie ('v' = voorkeursvolgorde). ${ }^{7}$

(6a) v [morgen] kom ik je [om [15.00 uur]] halen

(6b) [om [15.00 uur]] kom ik je [morgen] halen

(7a) v [morgen] kom ik je halen [om [15.00 uur]]

(7b) [om [15.00 uur]] kom ik je halen [morgen]

(8a) v ik kom je [morgen] halen [om [15.00 uur]]

(8b) ik kom je [om [15.00 uur]] halen [morgen]

We concluderen dat de syntagmatiek hier distinctief is op het iconische vlak: de voorkeursvolgorde morgen voor om 15.00 uur reflecteert de 'habit' het complexe te benaderen door uit te gaan van het minder complexe, eerder dan omgekeerd. Iconische volgordes dragen noch taalkundige, nog pragmatische betekenis. Dit sluit echter niet uit dat ze een bijdrage zouden kunnen leveren aan het decodeerproces van de ontvanger. Alleen experimenteel onderzoek kan hier eventueel een licht op werpen.

\section{Taalkundige factoren: taalgebonden, maar niet situatiegebonden}

Taalkundige factoren betreffen zowel de syntactische als de semantische verbinding tussen een woordgroep $\mathrm{x}$ en een woordgroep $\mathrm{y}$. Toegepast op woordvolgorde betekent dit dat de positie van een woordgroep x als een markering wordt beschouwd van de syntactische of van de semantische verbinding met y. We spreken dan respectievelijk van de syntactische of van de semantische functie van x. Taalkundige factoren zijn taalgebonden, maar niet situatiegebonden. Ter illustratie beperken we ons hier tot een korte uitwerking van een syntactisch voorbeeld, namelijk de subjectsfunctie. ${ }^{8}$ In het Nederlands bestaat de robuuste regel onder (9).

${ }^{7}$ De gepresenteerde acceptabiliteitsoordelen vanaf (6a) zijn tot stand gekomen op grond van een schriftelijk informantenonderzoek $(n=16$ per taal). In deze bijdrage betekent acceptabel: $\geq 12$ van de 16 informanten vinden de zinsuiting acceptabel of min of meer acceptabel. Onacceptabel staat voor: $\leq$ 4 van de 16 informanten vinden de zinsuiting acceptabel of min of meer acceptabel, aangegeven door * voor het voorbeeld. Het label twijfelachtig (?) wordt gereserveerd voor de resterende zinsuitingen. Het interval tussen 12/16 en 4/16 is significant op het 95\%-niveau (Van Wijk 2008).

${ }^{8}$ Een bekend voorbeeld van een semantische functie gemarkeerd door volgorde vormen de zogenaamde inherente bepalingen, beregeld door het Inherentieprincipe (Pekelder 2015). We komen hier op terug in paragraaf 5. 
(9) Het nominale subject gaat binnen het middenstuk van hoofd- of bijzin vooraf aan het nominale direct object (Nieuwborg 1968; Pekelder 2014). ${ }^{9}$

Dat het hier inderdaad om een niet situatiegebonden volgordeverschijnsel gaat, blijkt uit de observatie dat (10a) onder elke communicatieve situatie de aangegeven volgorde zal moeten vertonen, wil de ouders subject, en de leraren direct object zijn.

(10a) Gisteren hebben de ouders de leraren gesproken

Anders geformuleerd: de syntagmatiek is distinctief op het syntactische vlak: de volgorde SUB-DOB markeert hier de subjectsrelatie van de ouders met het verbale predicaat. Merk op dat dit syntactisch principe middenstukgebonden is. Zie (10b) waar het zonder explicitering van de communicatieve situatie niet duidelijk is welke van de twee aanwezige NP's subject of direct object is.

(10b) De ouders hebben de leraren gisteren gesproken

In tegenstelling tot een iconisch principe als het Complexiteitsprincipe zijn syntactische principes taalgebonden. Als we immers naar een verwante taal als het Frans kijken, dan constateren we dat de subjectfunctie anders gemarkeerd wordt. ${ }^{10}$ Deze taal bezit namelijk geen verbale tang en derhalve geen middenstuk. Er is daarentegen sprake van een zogenaamde amas verbal. Dat wil zeggen: een conglomeraat van verbale vormen dat slechts onder strikte voorwaardes doordringbaar is, maar nooit door een nominaal subject of direct object (Gerdes en Kahane 2006). Dit betekent dat er twee zones overblijven voor de plaatsing van nominaal subject en direct object: een pre- en een postverbale zone. Het blijkt dat de preverbale zone in de overgrote meerderheid van de gevallen het subject bevat en de postverbale zone in 100\% van de gevallen het direct object (Martinet 1985; Builles 1998). ${ }^{11}$ Zie (11a).

(11a) Jean bat Paul

Hier is Jean, geheel onafhankelijk van de communicatieve situatie, subject en Paul direct object. Als het Franse subject echter in de postverbale zone staat, heeft het de neiging het direct object te volgen. Zie le lierre qu'il avait planté cinq

${ }^{9}$ Maar psych-verbs lokken bij voorkeur DOB-SUB uit (Kijonkova 2016).

${ }^{10}$ Het Nederlands en het Frans zijn verwant in die zin dat ze beide Indo-Europees zijn.

11 Voor het Nederlands zijn de percentages respectievelijk: minder dan $50 \%$ op de eerste zinsplaats en iets meer dan $0 \%$ in het derde stuk (Nieuwborg 1968). Het subject kan in uitzonderlijke gevallen namelijk op de laatste zinsplaats staan, bijvoorbeeld in rouwberichten (Godin 2005). 
ans auparavant in (11b), un frisson d'attente et d'émotion anxieuse in (11c) en le compagnon du devoir in (11d). Als het subject daarentegen minder complex is dan het direct object, lijkt het bij voorkeur aan het direct object vooraf te gaan. Zie leurs invalides in (11e) (Le Goffic 1993; Korzen 1996; Muller 2008).

(11b) Peut-être enlaçait déjà la tonnelle le lierre qu'il avait planté cinq ans auparavant

(11c) C'est alors que parcourut l'auditoire un frisson d'attente et d'émotion anxieuse

(11d) Pendant de longues années parcourait la France sans jamais rentrer chez lui le compagnon du devoir

(11e) C'est chez eux que trouvent leurs invalides la fameuse 'loi de l'offre et de la demande' et vingt autres vieilles éclopées de cet ordre

We concluderen dat de syntagmatiek zowel in het Frans als in het Nederlands distinctief kan zijn op het syntactische vlak, namelijk daar waar het gaat om de herkenning door de ontvanger van de subjectsfunctie. De regel subject-voordirect-object geldt in het Nederlands onder de voorwaarde dat beide functies in het middenstuk staan. In het Frans daarentegen gaat deze regel alleen op als de functies worden gescheiden door de amas verbal.

\section{Pragmatische factoren: situatie- en taalgebonden}

Pragmatische factoren zijn per definitie situatiegebonden. Ze betreffen immers de verbinding tussen een woordgroep $\mathrm{x}$ en een element $\mathrm{y}$ in de communicatieve situatie. Toegepast op woordvolgorde betekent dit dat de positie van een woordgroep x als een markering wordtbeschouwdvan de pragmatische verbinding mety. ${ }^{12}$ We spreken dan van de pragmatische functie van $\mathrm{x}$. Zoals we in deze paragraaf aannemelijk proberen te maken, zijn pragmatische factoren tevens taalgebonden. Ter illustratie kijken we naar een bekend pragmatisch principe, i.c. het Functioneel Zinsperspectief, dat in het Frans eenvoudig traceerbaar is. In het Nederlands daarentegen is dit principe lang niet altijd werkzaam omdat het onder bepaalde condities overruled wordt door andere volgordeprincipes zoals het Inherentieprincipe en het Complexiteitsprincipe. De door Van Belle e.a. gepresenteerde definitie van het Functioneel Zinsperspectief is dus niet adequaat:

Het komt er, eenvoudig gezegd, op neer dat zinnen doorgaans [vet, JP] zo opgebouwd zijn dat zinsdelen die nieuwe informatie aanbrengen, achteraan staan, terwijl zinsdelen die 'bekende' informatie bieden, vooraan, of toch in de eerste zinshelft staan. Anders geformuleerd: het

12 Voor het Nederlands beperken we ons hier tot de woordvolgorde binnen het middenstuk en laten de eerste en laatste zinsplaats bijgevolg buiten beschouwing. 
thema ('thème' of 'topic') gaat aan het rema ('rhème' of 'comment') vooraf (Van Belle e.a. 2011: 7). ${ }^{13}$

Daar komt bij dat er een belangrijk element ontbreekt: het rhema in het Nederlands draagt systematisch het zogenaamde neutrale zinsaccent (Verhagen 1986; Florijn 1992; Haeseryn e.a. 1997; Rasier 2004). ${ }^{14}$

Kijken we nu naar (12a), dan lijkt het Functioneel Zinsperspectief op het eerste gezicht gerespecteerd te worden. ${ }^{15}$

(12a) A Waar ben je de dag ervoor naartoe gegaan?

B1 Ik ben [[de dag] ervoor] [naar [Antwerpen]] gegaan

B2 *Ik ben [naar [Antwerpen]] [[de dag] ervoor] gegaan

We constateren immers dat antwoord B1 waar de gerhematiseerde woordgroep naar Antwerpen achteraan in het middenstuk staat, acceptabel is in tegenstelling tot antwoord B2. Zie echter (12b).

(12b) A Wanneer ben je naar Antwerpen gegaan?

B1 Ik ben [[de dag] ervoor] [naar [Antwerpen]] gegaan

B2 *Ik ben [naar [Antwerpen]] [[de dag] ervoor] gegaan

We zien nu dat het Functioneel Zinsperspectief overtreden wordt: de gerhematiseerde woordgroep de dag ervoor mag niet achter naar Antwerpen staan. Vergelijk B1 en B2. De conclusie die we hieruit moeten trekken is dat de woordvolgorde in het onderhavige geval niet distinctief is op het pragmatische vlak. Wat er in (12a)-(12b) gebeurt, is dat het Functioneel Zinsperspectief wordt overruled door het zogenaamde Inherentieprincipe. ${ }^{16}$ In (12a) levert dat geen conflict op want beide principes zorgen er in principe voor dat naar Antwerpen naar het eind van het middenstuk wordt verplaatst. Vergelijk B1 en B2. In (12b) daarentegen ontstaat er een conflict tussen beide principes: het Inherentieprincipe maakt dat naar Antwerpen naar achteren gaat, terwijl het Functioneel Zinsperspectief er in principe voor zou moeten zorgen dat de dag ervoor naar achteren schuift.

13 Zoals bekend beschikt het Nederlands over diverse andere middelen om de functies rhema en thema te markeren: een gekloofde zin, een pseudo-gekloofde zin, een focuspartikel of een contrastief zinsaccent (Haeseryn e.a. 1997).

${ }^{14}$ Het neutrale zinsaccent treedt op in niet contrastieve uitingen, dat wil zeggen uitingen zonder echo-effet (Pekelder 2014).

${ }^{15}$ De Nederlandse data onder (12a)-(13c) zijn, net zoals de Franse data onder (14a)-(15b), laboratoriumzinnen. In natuurlijk taalgebruik ligt het meer voor de hand om in de onderhavige situaties het thema niet in het antwoord te herhalen.

${ }^{16}$ Dit taalkundige principe houdt eenvoudig gezegd in dat inherente woordgroepen zoals de richtingsbepaling naar Antwerpen verplicht adjacent zijn met de (positie van de) verbale rest (in bijzinnen de verbale groep) (Pekelder 2015). 
Vergelijk B1 en B2. Omdat het laatste antwoord niet acceptabel is, verschuift het neutrale zinsaccent in B1 naar voren om de dag ervoor alsnog als rhema te markeren. ${ }^{17} \mathrm{Zie}(12 \mathrm{c})$, waar de onderstreping het neutrale zinsaccent aangeeft.

(12c) A Wanneer ben je naar Antwerpen gegaan?

B Ik ben [[de dag] ervoor] [naar [Antwerpen]] gegaan

Zie vervolgens (13a).

(13a) A Hoe laat kom je me morgen halen?

B1 v Ik kom je [morgen] [om [15.00 uur]] halen

B2 Ik kom je [om [15.00 uur]] [morgen] halen

Opnieuw lijkt (13a) conform te zijn aan het Functioneel Zinsperspectief. De rhematische woordgroep om 15.00 uur staat immers bij voorkeur achter de thematische woordgroep morgen. Vergelijk B1 en B2. Zoals (13b) echter laat zien, is dit gezichtsbedrog.

(13b) A Wanneer kom je me om 15.00 uur halen?

B1 Ik kom je [morgen] [om [15.00 uur]] halen

B2 ?Ik kom je [om [15.00 uur]] [morgen] halen

De rhematische woordgroep morgen kan moeilijk achter de thematische woordgroep om 15.00 uur staan. Vergelijk B1 en B2. Met andere woorden: het Functioneel Zinsperspectief wordt opnieuw overtreden. De conclusie luidt wederom dat de woordvolgorde hier niet distinctief is op het pragmatische vlak. In (13a)-(13b) wordt dit principe overruled door het voornoemde Complexiteitsprincipe. In (13a) levert dat geen conflict op want beide principes zorgen ervoor dat om 15.00 uur bij voorkeur naar het eind van het middenstuk verplaatst wordt. Vergelijk B1 en B2. In (13b) daarentegen ontstaat er een conflict. Het Complexiteitsprincipe zorgt er immers voor dat om 15.00 uur naar achteren gaat, terwijl het Functioneel Zinsperspectief er in principe voor zou moeten zorgen dat morgen naar achteren schuift. Omdat dat laatste slechts met moeite lukt, zie B2, verschuift het neutrale zinsaccent in B1 naar voren om morgen alsnog als rhema te markeren. Zie (13c).

(13c) A Wanneer kom je me om 15.00 uur halen?

B Ik kom je [morgen][om [15.00 uur]] halen

${ }^{17}$ Dat het neutrale zinsaccent in het Nederlands inderdaad mobiel is, is tevens observeerbaar in de buurman heeft de buurvrouw blijkbaar gefotografeerd, waar het modale bijwoord blijkbaar geen neutraal zinsaccent kan dragen. Het verschuift dan ook naar achteren en komt terecht op de verbale rest gefotografeerd (Verhagen 1986). 
Zoals vermeld is het Functioneel Zinsperspectief, in tegenstelling tot het Nederlands, in het Frans eenvoudig traceerbaar. Zie (14a)-(14b) die zonder meer conform zijn aan dit principe.

(14a) A Où est-il parti hier midi?

B1 Il est parti [pour [Anvers]] [hier [midi]]

$\mathrm{B} 2 \mathrm{v}$ il est parti [hier [midi]] [pour [Anvers]]

(14b) A Quand est-il parti pour Anvers?

B1 v Il est parti [pour [Anvers]] [hier [midi]]

B2 Il est parti [hier [midi]] [pour [Anvers]]

De rhematische woordgroep pour Anvers in (14a) staat immers bij voorkeur achter de thematische woordgroep hier midi, vergelijk B1 met B2, terwijl de rhematische woordgroep hier midi in (14b) bij voorkeur achter de thematische woordgroep pour Anvers staat, vergelijk B1 met B2. Dit heeft tot gevolg dat het Inherentieprincipe wordt overtreden. In voorkeursvolgorde B2 van (14a) is de inherente richtingsbepaling pour Anvers immers niet adjacent met het verbale predicaat parti. Verder wijzen we erop dat ook het Complexiteitsprincipe overtreden lijkt te worden. Zie daarvoor (15a)-(15b).

(15a) A Où est-il parti hier?

B1 Il est parti [pour [Anvers]] [hier]

$\mathrm{B} 2 \mathrm{v}$ il est parti [hier] [pour [Anvers]]

(15b) A Quand est-il parti pour Anvers?

B1 v Il est parti [pour [Anvers]] [hier]

B2 Il est parti [hier] [pour [Anvers]]

Dat de complexere, rhematische woordgroep pour Anvers in (15a) bij voorkeur achter de minder complexe, thematische woordgroep hier staat, is weliswaar compatibel met het Complexiteitsprincipe, maar volgt uit het Functioneel Zinsperspectief. Vergelijk de antwoorden B1 en B2. Deze observatie wordt bevestigd door (15b) waar de minder complexe, rhematische woordgroep hier bij voorkeur achter de thematische en complexere woordgroep pour Anvers staat en dus tegen het Complexiteitsprincipe ingaat. Vergelijk opnieuw B1 met B2.

We concluderen dat de volgorde in het Nederlands in de bestudeerde uitingen pragmatisch niet distinctief is. Het ziet ernaar uit dat de ontvanger voor de decodering van het rhema eerder een beroep doet op een fonologische markering, namelijk het neutrale zinsaccent. In het Frans daarentegen staat het rhema in de 
gepresenteerde data achteraan. Voor de Franse ontvanger is de positie van de gerhematiseerde woordgroep derhalve distinctief op het pragmatische vlak.

\section{Een fonologisch contrast}

De vraag rijst ten slotte waarom in de behandelde Nederlands data het Inherentieprincipe en het Complexiteitsprincipe lijken te prevaleren boven het Functioneel Zinsperspectief, terwijl we in onze Franse data het omgekeerde fenomeen zien. Een mogelijke hypothese die ons inziens onderzocht zou moeten worden is dat het verschil tussen de Nederlandse data in (12a)-(13c) en de Franse data in (14a)-(15b) samenhangt met een fonologisch verschil tussen beide talen. Het Nederlands bezit een vast woordaccent: binnen een en hetzelfde woord valt het accent op een vaste lettergreep. Het Frans daarentegen heeft een vrij woordaccent: binnen een en hetzelfde woord is het accent vluchtig. Afhankelijk van de communicatieve situatie kan het verplaatst worden van de ene lettergreep naar de andere (Matte 1982; Stridfeldt 2005). Dit verschil tussen de twee talen is er mogelijk verantwoordelijk voor dat het Nederlands, in tegenstelling tot het Frans, een zinsaccent heeft. Het parasiteert immers het vaste woordaccent van een van de woorden binnen de pragmatisch meest prominente woordgroep van de zinsuiting, het rhema. Aangezien elk woord binnen de uiting een vast accent draagt, is het zinsaccent niet plaatsgebonden en kan het rhema elders gemarkeerd worden dan aan het eind van het middenstuk. Het Frans dat geen zinsaccent kent, wordt gekarakteriseerd door een woordgroepsaccent: elke woordgroep binnen de zinsuiting draagt een accent op de laatste lettergreep. In niet contrastieve zinsuitingen verdringt dit woordgroepsaccent voornoemde vrije woordaccenten (Matte 1982; Stridfeldt 2005). Dit heeft tot gevolg dat het rhema niet fonologisch gemarkeerd kan worden. Naast een aantal andere procédés gebruikt het Frans derhalve de laatste postverbale positie voor de markering van het rhema. ${ }^{18}$

\section{Conclusies}

In deze bijdrage hebben we een methodologische reflectie gepresenteerd met betrekking tot de vraag hoe de verschillende factoren die woordvolgorde beïnvloeden, onderscheiden kunnen of wellicht moeten worden. Volgorde bestaat in eerste instantie niet voor de taal maar ontstaat door de taal vanwege haar vocale karakter. Onze hypothese is dat deze zogenaamde temporele volgorde onderhevig is aan drie types factoren: iconische, taalkundige - i.e. syntactische en semantische

${ }^{18}$ Net zoals het Nederlands gebruikt het Frans tevens (pseudo-)gekloofde zinnen en focuspartikels. 
- en pragmatische factoren. Iconische factoren projecteren bepaalde habits op de woordvolgorde, zoals de tendens om het complexe te benaderen vanuit het minder complexe, eerder dan omgekeerd: het Complexiteitsprincipe. Deze factoren zijn in principe noch taal- noch situatiegebonden. Ze dragen derhalve noch taalkundige, nog pragmatische betekenis. Dit sluit echter niet uit dat ze een bijdrage zouden kunnen leveren aan het decodeerproces van de ontvanger. Dit zou verder experimenteel onderzocht moeten worden. Taalkundige factoren betreffen de syntactische en semantische verbindingen tussen woorden en tussen woordgroepen. Ze zijn taalgebonden omdat ze bepaald worden door de grammatica van een specifieke taal. Ze zijn tevens niet situatiegebonden. Zo gedraagt het Nederlandse subject zich positioneel bijvoorbeeld anders dan het Franse subject. Binnen het middenstuk herkent de Nederlandstalige ontvanger het subject op basis van de regel subject-voor-direct-object, terwijl de Franstalige ontvanger in dezen slechts een beroep op woordvolgorde doet als het subject door de amas verbal van het direct object wordt gescheiden. In beide gevallen heeft de communicatieve situatie daar geen enkele invloed op. De pragmatische factoren ten slotte hangen samen met de communicatieve situatie. Ze zijn bijgevolg situatiegebonden. Ze zijn daarnaast mogelijk ook taalgebonden. Onze data laten zien dat het Functioneel Zinsperspectief in het Nederlands overruled kan worden door het Complexiteitsprincipe en het Inherentieprincipe. Teneinde in dat geval het rhema te bepalen, doet de ontvanger een beroep op een fonologische parameter, het neutrale zinsaccent. Dit accent valt weliswaar bij voorkeur op de woordgroep vlak voor de (positie van de) verbale rest, maar is in principe mobiel. Het rhema wordt dus niet per se positioneel gemarkeerd. In het Frans echter bestaan volgordeverschijnselen die erop wijzen dat het Functioneel Zinsperspectief in bepaalde situaties zowel het Complexiteitsprincipe als het Inherentieprincipe overruled. Een mogelijke hypothese die ons inziens onderzocht zou moeten worden, is of dit samenhangt met een fonologisch verschil tussen beide talen. In tegenstelling tot het Nederlands bezit het Frans geen neutraal zinsaccent, maar een woordgroepsaccent. Dit maakt de fonologische markering van het rhema lastig. De ontvanger doet daarom, onder andere, een beroep op volgorde en decodeert de gerhematiseerde woordgroep aan het eind van de zinsuiting als rhema.

\section{Bibliografie}

Abeillé, Anne, \& Danièle Godard (2006): “La légèreté comme déficience de mobilité en français". Lingvisticae Investigationes 29:1, 11-24.

Behaghel, Otto (1909): “Beziehungen zwischen Umfang und Reihenfolge von Satzgliedern”. Indogermanische Forschungen 25, 110-142.

Belle, William van, e.a. (2011): "Nederlandse grammatica voor Franstaligen", laatst geraadpleegd op 6.10.2017<http://www.ling.arts.kuleuven.be/NGF_N/NGF_NL.htm.>. 
Builles, Jean-Michel (1998): Manuel de linguistique descriptive. Le point de vue fonctionnaliste. Paris: Nathan.

De Groot, Willem (1949): Structurele syntaxis. Den Haag: Servire.

Dik, Simon (1997): The Theory of Functional Grammar I and II. Twee delen. Berlin: Mouton de Gruyter.

Ebeling, Carl (2006): Semiotaxis. Over theoretische en Nederlandse syntaxis. Amsterdam: AUP.

Florijn, Arjen (1992): Beregeling van Nederlandse woordvolgorde. Amsterdam: Rozenberg Publishers.

Gerdes, Kimen, \& Sylvain Kahane (2006): “L'amas verbal au cœur d'une modélisation topologique du français". Linguisticae Investigationes 29:1, 75-89.

Godin, Pierre (2005): "Achteropplaatsing van het substantivisch onderwerp in het Nederlands (met bijzondere aandacht aan rouwberichten)". In: Philippe Hiligsmann e.a. (red.), Woord voor woord, Zin voor zin, Liber Amicorum voor S. Theissen. Gent: KANTL, 147-163.

Haeseryn, Walter, e.a. (1997): Algemene Nederlandse Spraakkunst. Groningen-Deurne: Martinus Nijhoff-Wolters Plantyn.

Kijonkova, Jana (2016): "De gevolgen van de valentie van psych-verbs voor de woordvolgorde in het middenstuk". Roczniki Humanistyczne 64, 29-45.

Korzen, Hanne (1996): "La place du sujet non clitique dans la construction inversée". Langue Française 111, 59-82.

Le Goffic, Pierre (1993): Grammaire de la Phrase Française. Paris: Hachette.

Martinet, André (1985): Syntaxe Générale. Parijs: Armand Colin.

Matte, Edouard (1982): Histoire des modes phonétiques du français. Genève: Droz.

Muller, Claude (2008): "Réflexions sur l'ordre des mots en français (les constituants majeurs de l'énoncé)". In: Jacques Durand e.a. (red.), Congrès Mondial de Linguistique Française CMLF'08. Parijs: Institut de Linguistique Française.

Nieuwborg, Elie (1968): De distributie van het onderwerp en het lijdend voorwerp in het huidige geschreven Nederlands in zijn A.B.-vorm. Antwerpen: Plantyn.

Paardekooper, Piet (1986): Beknopte ABN-syntaksis. Eindhoven: uitgave in eigen beheer.

Paul, Hermann (1920): Prinzipien der Sprachgeschichte. Halle: Niemeyer.

Pekelder, Jan (2002): Décodage et interprétation. Ordres linguistique, iconique et pragmatique en néerlandais contemporain. Louvain-la-Neuve: Peeters.

Pekelder, Jan (2014): "Het Nederlandse subject een taalteken? Over SUB-PV-DOB- en PV-SUBDOB-strings". In: Freek van de Velde (red.), Patroon en argument. Een dubbelfeestbundel bij het emeritaat van William van Belle en Joop van der Horst. Leuven: Universitaire Pers Leuven, 271-284.

Pekelder, Jan (2015): "Le Principe d'Inhérence revisité. Linéarisation des compléments d'objet direct et de direction en néerlandais". Travaux linguistiques du Cerlico 28, 155-166.

Rasier, Laurent (2004): "De zinsaccentuering in het Nederlands: een verkenning over de grenzen tussen (toegepaste) taalkunde en didactiek heen". In: Arie Gelderblom (red.), Neerlandistiek de grenzen voorbij. Münster: Nodus-Publikationen, 303-322.

Stridfeldt, Monika (2005): La perception du français oral par des apprenants suédois. Umeå: Umeå universitet.

Uhlenbeck, Eugenius (1982): "Enige beschouwingen over verleden, heden en toekomst van de taalwetenschap in Nederland". Forum der Letteren 23:3, 163-183.

Van der Horst, Joop (1995): Analytische taalkunde. Groningen: Martinus Nijhoff.

Van der Lubbe, Hendricus (1978): Woordvolgorde in het Nederlands. Een synchrone structurele beschouwing, vierde druk. Assen: Van Gorcum.

Van Wijk, Carel (2008): Toetsende statistiek. Basistechnieken. Een praktijkgerichte inleiding voor onderzoekers van taal, gedrag en communicatie. Bussum: Coutinho. 
Verhagen, Arie (1986): Linguistic Theory and the Function of Word Order in Dutch: A Study on Interpretive Aspects of the Order of Adverbials and Noun Phrases. Dordrecht: Foris publications.

Wasow, Thomas (1997): "Remarks on grammatical weight". Language Variation and Change 9, 81-105. 